\title{
LA FAMILIA Y EL CAMBIO POLITICO EN ESPAÑA
}

\author{
Por JULIO IGLESIAS DE USSEL
}

\begin{abstract}
SUMARIO
I. El cambio en la familia.-II. Los cambios en la Iglesia española.III. LAS ESTRATEgIAS POLíticas ANTE LA LEGISLACIÓN FAMILIAR.
\end{abstract}

La familia siempre ha sido el centro neurálgico de las transformaciones sociales. Los pensadores revolucionarios de todo signo, a la hora de proyectar la nueva sociedad como cuestión previa, abordan el matrimonio, las relaciones familiares, el papel de la mujer dentro y fuera de la familia, la educación y crianza de los hijos, el divorcio, la ilegitimidad, la sexualidad, los derechos de sucesión, etc. El siglo XIX nos ha legado abundantes replanteamientos de todos estos aspectos del sistema familiar, que, igualmente, se encuentran en la dilatada tradición histórica de la literatura utópica. Los cambios en la familia se contemplan como imprescindibles para la construcción de una nueva sociedad. Una nueva familia es el instrumento o el objetivo final de una nueva organización social y política, de un nuevo horizonte histórico en definitiva.

En el terreno de la práctica política, la situación es semejante. Todo cambio político ha venido acompañado de transformaciones en la legislación familiar. Primero, porque, al repercutir en la vida cotidiana de la población, se convierte en espacio estratégico de la nueva realidad política. En segundo lugar, porque esos cambios familiares pueden instrumentarse como símbolo privilegiado del propio cambio político. Los cambios en la legislación familiar pueden desempenar, en efecto, un importante papel en la estrategia simbólica de ruptura con el pasado. $\mathrm{E}$, incluso, gracias a ellos, proteger o enmascarar otras continuidades — políticas o económicas- más difíciles de 
transformar o de hacerles frente. Si además las innovaciones legales producen reacciones críticas por parte de sectores vinculados a la anterior situación política, será más acusada todavía su eficacia simbólica de quiebra aparente con el pasado. Pero, en tercer lugar, el sistema familiar es también el espacio privilegiado para fomentar el cambio social o la innovación para el futuro. Los intentos por implantar nuevos valores políticos o sociales pasan por alteraciones, desde en la forma de llamarse — «ciudadano», "camarada», "compañero»- a las relaciones de poder entre estratos sociales. Y, en este ámbito, la modificación drástica del sistema familiar se convierte en objetivo privilegiado.

Es la familia, en efecto, el primer núcleo de transmisión de valores sociales; por tanto, la futura estabilidad de la nueva situación política estará vinculada a la modificación de los contenidos transmitidos por ella. La sintonía entre los valores familiares y políticos constituye la garantía de supervivencia del nuevo sistema. De ahí la necesidad de influir desde el sistema político en el familiar: para romper sus vínculos con el pasado e instrumentarla al servicio de la nueva dinámica política. El papel, por ejemplo, de los cambios en la regulación de la legitimidad de los hijos - casi siempre con escasa duración - es notorio en distintas revoluciones de los siglos XIX y $\mathrm{xx}$ como medio para la consolidación del valor de la igualdad (1).

En España, sin embargo, la familia, actual y del pasado, se encuentra huérfana de reflexión política. Desatención que contrasta aún más con la virulencia y agrias polémicas públicas que, a menudo, han rodeado los cambios legales sobre la familia en nuestro país. Ni las controversias suscitadas por documentos del Vaticano en materia de familia, ni las posturas del movimiento feminista, ni las cuestiones abiertas por la ingeniería genética, ni el papel otorgado a la familia por el franquismo - al menos ideológicamentehan incitado más que reflexiones marginales entre los especialistas. El debate y la polémica no han trascendido de las páginas de la prensa.

Esta situación me parece particularmente grave. Acaso el franquismo no alcance a interpretarse en su totalidad sin analizar las peculiaridades de la institución familiar ni su papel en el sistema. Pero tampoco la propia transición política. Los cambios políticos repercuten en la famila, pero ésta no es mero sujeto pasivo. La familia ha influido, a su vez, en el proceso de cambio político. Piénsese, por ejemplo, en las continuidades generacionales en la

(1) Un análisis político puede yerse en R. LAUB Coser y L. A. Coser: «The principle of Legitimacy and its patterned infringement in social revolutions», en M. Sussman y B. Cogswell: Cross-National Family Research, Leiden, Bill, 1972, págs. 119-131. 
afiliación y voto a partidos políticos (2). $\mathrm{O}$, en niveles más profundos e imprecisables hoy, en el carácter consensual y de pacto en la transición política. Posiblemente las familias han transmitido la memoria histórica del trauma de la guerra civil, como «miedo al pasado», influyendo también - felizmenteen que éste no se reproduzca. Un estudio de socialización o de historia oral arrojaría luz al respecto.

En todo caso, el análisis de la modernización de la legislación familiar importa por tres tipos de razones. En primer lugar, por el propio carácter de la transición política, que implicó a otras muchas instituciones y sectores sociales. Jiménez Blanco ha escrito al respecto que sla ruptura política con el franquismo se acompañó de la ruptura con otra serie de cosas, que en la mente de jóvenes de los años cincuenta se percibieron como inextricablemente asociadas con el franquismo. En este sentido, la ruptura política se vio acompañada para no pocas gentes con una ruptura religiosa, social y cultural, que denominaremos 'constelación de rupturas'. Con esta expresión queremos indicar que la ruptura política no se limitó al paso de la dictadura a la democracia, sino que afectó a la cultura y a la estructura social de una manera, en ocasiones, tan ilógica como efectiva. En la actualidad estamos en mejores condiciones - transcurridos más de diez años del proceso- de describir las diferentes rupturas en constelación, que de explicar y comprender la lógica interna que dé razón de por qué todas esas rupturas se produjeron al mismo tiempo» (3). Pues bien: en el caso de la familia, junto a la quiebra de comportamientos sociales se produce también la ruptura — bastante radical, como luego se verá- con la legislación familiar vigente durante el franquismo.

En segundo lugar, resulta importante examinar el cambio por la institución que implica. La familia nunca ha sido en España un mero ámbito de la vida cotidiana de los ciudadanos. Se le ha otorgado una relevancia especial y ha estado siempre bajo el control de la Iglesia. Esta ha cedido o perdido desde el siglo xvin múltiples ámbitos de control y supervisión en la sociedad. Sin embargo, nunca ha abandonado la pretensión de mantener dentro de su órbita, directamente o por mediación del poder civil, la orientación de la legislación familiar. También en este aspecto la transición política significa la ruptura con una constante histórica, con muy pocas excepciones, en la sociedad española.

(2) Véase, por ejemplo, J. M. Maravall: La política de la transición, 2." ed., Ed. Taurus, Madrid, 1984.

(3) J. J. Blanco, en la obra colectiva Juventud vasca 1986, Vitoria, 1986, pág. 506. Véase también R. DEL AgUILA y R. Monroro: El discurso político de la transición española, CIS, Madrid, 1984, págs. 208-227. 
$Y$ en tercer lugar, por la extraordinaria repercusión que alcanzaron precedentes de cambios en la regulación de la familia. Anteriores iniciativas en nuestro pasado histórico dieron lugar a conflictos políticos, tensiones con la Iglesia e incluso importantes movilizaciones sociales. En suma, fueron realizada con altos costes políticos y posiblemente con reducidas consecuencias sociales. La introducción del matrimonio civil y la legislación de la Segunda República sobre la familia pueden ser dos ejemplos para reflexionar.

\section{a) El matrimonio civil}

La Ley de Matrimonio Civil de 1870 fue el primer intento de sustituir a la Iglesia en la regulación del matrimonio. Introdujo durante varios años - hasta su derogación en 1875- el matrimonio civil obligatorio para todos los ciudadanos, suprimiendo los efectos civiles del contraído de modo religioso (4).

Fruto de la Revolución de septiembre de 1868, su contenido rompió tajantemente con el control eclesiástico de la legislación familiar y matrimonial. Desde 1564, en efecto, había sido el matrimonio canónico la única forma válida en España. A partir de dicha fecha, el Estado intentó sustituir a la Iglesia en el control del matrimonio.

¿Existía demanda social para la introducción del matrimonio civil obligatorio? Desde luego no es la demanda mayoritaria dirigida por los municipios a las Cortes. Sólo se plantea en un 5 por 100 de las peticiones, con mucha menor frecuencia de otras con contenido socioeconómico. Sin embargo, otros datos revelan la existencia de una cierta opinión pública sobre el matrimonio civil. Por una parte, las Juntas Revolucionarias locales recogían en sus manifiestos las demandas de libertad de cultos y matrimonio civil. En segundo lugar, en las peticiones elevadas a las Cortes por obispos y párrocos se solicita que no se modifique el matrimonio canónico. En tercer lugar, la autorización de matrimonios civiles en diversas localidades —e incluso la publicación de normas específicas que lo regulan mediante bandos municipales- antes de aprobarse la Constitución y la propia Ley de 1870 muestran que la cuestión no resultaba indiferente para ciertos sectores de la sociedad española. Como resultado de ese espontaneísmo normativo se producen diversas interpelaciones al Gobierno en las Cortes, pidiendo el cese de tales uniones civiles autorizadas por los ayuntamientos. Pero fundadas en su ilegalidad y no en posturas contrarias a la existencia del matrimonio civil obligatorio.

En conjunto, estos hechos, brevemente apuntados, revelan la existencia de

(4) Sigo en este apartado a R. Roldán Verdejo: La Ley de Matrimonio Civil de 1870, Granada, 1980. 
aspiraciones en favor del matrimonio civil, que entonces se presenta como símbolo de ruptura e innovación social y consecuencia obligada de la libertad de cultos. Ya antes de la Constitución de 1869 se presentan proposiciones de ley solicitándolo, e inmediatamente después de aprobada, el propio Gobierno presenta un proyecto de ley donde se establece el matrimonio civil obligatorio. Pero la urgencia con que se aborda la cuestión no es social, sino política: aprovechar el ambiente revolucionario para imprimir una nueva orientación al Estado de la Revolución de 1868.

Existen, en efecto, diversos elementos para justificar la naturaleza política de la Ley de Matrimonio Civil. Empezando por sus propios límites, dicha ley excluye el divorcio y mantiene la indisolubilidad del matrimonio. El divorcio sí hubiera introducido elementos nuevos y radicales en la regulación de la familia. Sin embargo, queda excluido, y precisamente por no considerarlo necesario ni conveniente, dada la mentalidad católica predominante en la sociedad española. Sólo un futuro cambio en las costumbres permitirá plantear el divorcio. Es decir, en el propio debate parlamentario de la ley se plasman los límites que el estado de opinión implantan a las innovaciones legailes.

La misma conclusión se desprende de la reacción producida por la ley. El escrito remitido por el Episcopado a las Cortes en enero de 1870 hará referencia a que es contraria a los sentimientos y costumbres predominantes de los españoles. La oposición de la Iglesia, cuya influencia sobre la población, sobre todo rural, era innegable, logró mantener al matrimonio religioso como el verdadero matrimonio desde el punto de vista social. Y al matrimonio civil, si se celebraba, como un acto burocrático tras la ceremonia eclesiástica. El alcance del rechazo se manifiesta en que ya en 1874 y 1875 aparecen disposiciones legales autorizando se inscriban como legítimos los hijos de matrimonios contraídos sólo de forma religiosa. $Y$ en este mismo año se restablece la plena vigencia del matrimonio canónico y se reconocen efectos civiles a los contraídos desde 1870 . Es decir, se cierra el intento de regulación por los poderes civiles del matrimonio.

La cuestión resurge aún después, incluso con pretensiones mucho más modestas: únicamente facilitar el matrimonio civil de los bautizados, manteniendo pleno reconocimiento a los efectos del celebrado en forma religiosa. En 1906 se estableció al efecto que el matrimonio civil pudiera contraerse sin previa declaración de los contrayentes de no profesar la religión católica. El conde de Romanones, autor de la medida, ha descrito sus efectos: «No pude sospechar la estrepitosa protesta que levantó esta resolución; seguro estoy de que en ningún país del mundo, en pleno siglo $\mathrm{xx}$, se hubiera producido otra igual (...). El Episcopado no omitió medio para atacarme; hubo 
obispo, como el de Tuy, que no se detuvo ante los respetos más elementales debidos al poder público y me hizo blanco de los mayores vituperios, con tal arrojo, que hasta despertó en mi ánimo la simpatía. En una larga pastoral, deleitosa para las derechas, lo más suave que me llamó fue tonto (...). Con el de Tuy habían hecho causa común todos los obispos de España. A sus ataques siguieron los de varios Cabildos; el de Córdoba se destacó, con tal violencia que fue necesario procesarlo» (5). La medida - revocada dos años después-, con pretensiones limitadas a facilitar el matrimonio civil, provocó de nuevo toda suerte de ataques.

\section{b) La familia en la Segunda República}

La Segunda República introdujo cambios radicales en el tratamiento legal de la familia y la mujer. La Constitución, con la separación de la Iglesia y el Estado, modifico por completo los principios del derecho de familia. Implantó innovaciones que se adelantaron en tres décadas a las reformas introducidas desde finales de los años sesenta en países europeos desarrollados. La regulación del aborto o el divorcio por consentimiento mutuo (que entra en vigor en Francia en 1974) constituyen ejemplos suficientes de la orientación de la reforma.

Los conflictos desencadenados por las nuevas tendencias en la legislación familiar tuvieron su origen ya en la discusión de la Constitución republicana y se vincularon a la polémica sobre la cuestión religiosa. De hecho, ya al iniciarse el debate a la totalidad de los artículos referentes a la Iglesia, familia y enseñanza, Gil Robles anunció su propósito de revisión constitucional si quedaba aceptado - como así ocurrió- el proyecto. $Y$ es sabido que la aprobación del artículo 26 de la Constitución - sobre la cuestión religiosa- provocó la dimisión del presidente de la República, del ministro de Gobernación y la retirada del Parlamento de 37 diputados católicos.

Cuando, a continuación de estos acontecimientos, comienza la discusión del artículo sobre la familia, la suerte de su contenido estaba prejuzgado. Reforzó la convicción en la oportunidad de constitucionalizar el divorcio. Llevándolo a la Constitución, se obstaculizaban ulteriores tentaciones reformistas.

Los protagonistas políticos de la época han dejado en sus memorias abundantes testimonios de los esfuerzos de la Iglesia por mantener el statu quo de la legislación familiar. Era éste un aspecto central de sus demandas en las negociaciones. Y la importancia que otorgaba a la cuestión se mani-

(5) Conde de Romanones: Notas de una vida (1.a ed. 1928), Ed. Aguilar, Madrid, 1945, págs. 384-387. 
festó igualmente en sus posiciones públicas. Baste señalar que en cinco de los ocho documentos colectivos del Episcopado publicados entre 1931 y 1936 censuran con mayor o menor amplitud el cambio de la tradicional orientación jurídico-política sobre la familia. Uno de ellos, en julio de 1932, sobre el matrimonio civil y canónico, reiteró la obligatoriedad del matrimonio canónico y las sanciones que conlleva la inobservancia de la ley eclesiástica.

La Iglesia, en su oposición a la nueva legislación familiar, apeló a los riesgos de inestabilidad social que introducía la ruptura con la tradición. En la declaración del Episcopado de diciembre de 1931, "Los obispos ante la nueva Constitución», afirmaron: «La Iglesia no cesará de reivindicar (...) el reconocimiento oficial de su competencia, el acuerdo de la legislación canónica y civil y la supresión del divorcio, segura que labora eficazmente por la salud misma de la República, librándola de la depravación de las costumbres públicas, impidiendo la inmerecida humillación de la mujer, víctima y expósita segura de tales viciosas emancipaciones, enfrentando el culto a la carne a que conduce la práctica fácil y el deseo mórbido del divorcio, y of reciéndole, en cambio, por el matrimonio cristiano, una raza de ciudadanos que, animados de sentimientos honestos y educados en el respeto y el amor de Dios, se considerarán obligados a obedecer a los que justa y legítimamente mandan, a amar a sus prójimos y a respetar todo derecho de sus conciudadanos» (6).

Este texto desarrolla con precisión la concepción tradicional de la familia, que la República cambió por completo. Pero, ¿tuvieron repercusión en los comportamientos sociales las profundas innovaciones legales? Dada la escasa vigencia de la nueva legislación, resulta lógico pensar en una reducida incidencia colectiva. Existen numerosos indicios en este sentido, y en el caso del divorcio, está documentada la muy escasa utilización de la ley (7).

Frente a una realidad con bajo número de divorcios, se instrumentó, sin embargo, una campaña sosteniendo que un elevado número de matrimonios se divorciabani. $Y$ en ello colaboraron tanto las derechas como las izquierdas. Para las derechas, con ese argumento quedaban justificados sus intentos previos de oponerse a la nueva ley. Además, se utilizaba como prueba concluyente del grave atentado al fundamento de la familia, lo que equivalía - como se ha visto- a la ruina de la propia sociedad. Así, dar por hecho el elevado número de divorcios permitía cuestionar ante la opinión pública la legitimidad de un régimen con tan disolventes novedades.

(6) Recogido en J. IrIBarren (ed.): Documentos colectivos del Episcopado español, 1870-1974, BAC, Madrid, 1974, pág. 167.

(7) Véase al respecto I. Alberd: Historia y sociología del divorcio en España, CIS, Madrid, 1979. 
Pero para los divorcistas, igual instrumentación proporcionaba dar como real la frecuencia del divorcio. Significaba, en efecto, la prueba irrefutable de que la legislación laica de la República respondía a los verdaderos sentimientos del pueblo. La buena acogida a la legislación familiar ofrecía la oportunidad de censurar a posteriori la suprimida imposición de la legislación eclesiástica. Era prueba de la ilegitimidad de su imposición a la sociedad española.

En suma, el primer intento por sustituir la orientación tradicional de la legislación familiar se salda en un enfrentamiento con la Iglesia, intensas movilizaciones sociales en defensa y en contra y reducidos efectos reales en los comportamientos colectivos.

Con estos antecedentes, el cambio de la legislación familiar parecería destinado a generar nuevos conflictos, también en la transición política. Que en esta ocasión, al fin, no se hayan producido, se debe, en mi opinión, a la coincidencia de tres circunstancias merecedoras de examen: al cambio de la familia durante el franquismo; a la posición de la Iglesia, y a la estrategia de la reforma política.

\section{EL CAMBIO EN LA FAMILIA}

E1 franquismo significó la ruptura también en la orientación dada a la legislación familiar por la República. Una de las primeras demandas planteadas por la jerarquía eclesiástica fue, en efecto, la derogación del divorcio y la vuelta al control de la Iglesia del derecho de la familia. Así sucedio, y desde la guerra civil se fue restaurando la legislación vigente hasta 1931. Se anula la igualdad entre hijos legítimos e ilegítimos, se penalizan los anticonceptivos, adulterio y amancebamiento, se obstaculiza el trabajo de la mujer -sobre todo si es casada-, se prohíbe la coeducación, se fomentan las familias numerosas - si bien con medidas más simbólicas que efectivas-, se implanta el matrimonio religioso obligatorio para los bautizados, se otorga a la Iglesia la competencia para juzgar la separación y nulidad matrimonial, se establece la desigualdad de derechos en función del sexo fuera y dentro del matrimonio, el cual —según la Ley de 24 de abril de 1958 - «exige una potestad de dirección que la Naturaleza, la Religión y la Historia atribuyen al marido", etc. (8).

En to esencial, el marco jurídico de la familia permaneció con la misma

(8) Una síntesis de la legislación en este petíodo puede consultarse en S. DEL CAMPo: La política demográfica en España, Edicusa, Madrid, 1974. 
orientación hasta la transición política. Pero va a ser durante el franquismo cuando se pase de una sociedad de familias a una sociedad de individuos. El impulso de esta transformación proviene del cambio social acelerado por el desarrollo económico de los años sesenta. Manifestaciones decisivas para la familia de ese cambio aquí sólo puede citarse. Entre ellas, la concentración urbana, el acelerado descenso de población activa agraria e incremento en el sector industrial y de servicios, el aumento de trabajo extradoméstico de la mujer, da elevación de las tasas de escolarización de los dos sexos, la secularización en plena vigencia del nacional-catolicismo, el influjo de la emigración exterior y del turismo interior, la difusión de un cierto bienestar económico y aun de la sociedad de consumo en la clase alta, el cambio de la estructura ocupacional y la reducción del paro, etc. (9).

Estos cambios favorecieron o aceleraron transformaciones importantes en la dinámica de la familia española, pero en dirección opuesta a las directrices políticas, religiosas y la legislación vigente. Algunos aspectos deben resaltarse.

Desde 1960 desciende la edad media de matrimonio de los varones y las mujeres, e igualmente las diferencias de edad entre ambos. Es decir, el matrimonio se celebra, cada vez más, dentro de las cohortes generacionales más próximas.

Por otra parte, en esas mismas fechas, la tasa de nupcialidad (número de matrimonios por mil habitantes) alcanza sus máximos históricos, reduciéndose, por consiguiente, el celibato. Estas tendencias son relevantes. Se producen, en efecto, simultáneamente, a la flexibilización de las relaciones entre jóvenes de distinto sexo. Numerosas encuestas de opinión desde la década de los sesenta muestran la creciente permisividad en las relaciones sexuales prematrimoniales. Pero ni esta permisividad ni el cambio de comportamientos entre jóvenes reducen la frecuencia del matrimonio, sino al contrario. El descenso en la nupcialidad no se produce hasta 1975, y, en mi opinión, más como consecuencia de la crisis económica (que afecta sobre todo al primer empleo de los jóvenes) que a un rechazo abierto al matrimonio. La cohabitación sin vínculos de matrimonio religioso o civil es un fenómeno más reciente $y$, en todo caso, no explica por sí sola la magnitud del descenso de la nupcialidad en los últimos años.

Pero los cambios tuvieron lugar, igualmente, en aspectos difícilmente mensurables. Paulatinamente fueron desapareciendo todas las rigideces de los

(9) El cambio social está analizado con detalle en los sucesivos Informes Foessa; véase también J. F. Tezanos: "Cambio social y modernización en la España actual», en REIS, núm. 28, 1984. 
noviazgos tradicionales en la sociedad española, entre otras, su duración quedó acortada, y quizá se multiplicaron las experiencias previas antes de contraer matrimonio; frente a una etapa anterior en que al noviazgo se le consideraba experiencia única y excluyente, en el caso de la mujer sobre todo.

El cambio de hábitos en la interacción entre jóvenes (favorecida por la creciente escolarización de ambos sexos) ocasionó la pérdida de influencia directa de la familia en el control de la selección de cónyuge. La formación de parejas es resultado de las propias iniciativas entre jóvenes y no de imposiciones familiares. Como en otros países europeos, la familia continúa mediatizando indirectamente la elección (por su clase social, medio de residencia, etc.) y controlan de manera más rígida a las mujeres que a los varones. Pero la determinación de la pareja reside ya en procesos de selección al arbitrio de la dinámica de comportamientos juveniles.

Además, se han producido también cambios significativos en las cualidades consideradas importantes en la persona con la que desearían contraer matrimonio. Las encuestas sobre la juventud han abordado reiteradamente esta cuestión. Lo más destacado de la evolución entre 1960 y 1977 es el descenso de la importancia otorgada al papel de los factores religiosos y morales y el ascenso de la concedida a la educación, cultura y similitud de opiniones. Es decir, a aspectos que inciden en la dinámica de la relación interpersonal de la pareja.

Las relaciones sexuales prematrimoniales han ocasionado un significativo número de matrimonios por causa de embarazo previo. La «Encuesta de fecundidad» de 1977 revela que el 17 por 100 de las entrevistadas -en especial las menores de veintidós años- tuvieron su primer hijo antes del octavo mes de matrimonio. No es posible, sin embargo, determinar si se trata de matrimonios "provocados» (es decir, de parejas sin vínculos de noviazgo y, por tanto, no previstos) o «adelantados» (entre novios, pero no previsto en ese momento). La transición de las normas sexuales iniciada en la década de los sesenta permite formular la hipótesis de que en dichos años fueron sobre todo "provocados», y en los setenta, más frecuentemente los «adelantados».

Estas tendencias, desencadenadas o aceleradas en los años sesenta, significan, en definitiva, el paso de una relación de pareja fundada en lo personal más que en lo institucional. Los aspectos afectivos se convierten en determinantes de la elección conyugal y de la relación matrimonial. Los jóvenes asumen la responsabilidad de su futuro matrimonial con posibilidad de repetir las tentativas de consolidarla y al margen de injerencias familiares directas. En suma, la libertad de elección de pareja queda ampliada a todos los sectores de la sociedad española.

Los años sesenta significan, igualmente, el inicio de importantes transfor- 
maciones en las pautas de natalidad. Desde el final de la guerra civil, el Estado implantó numerosas medidas para fomentar la natalidad a través de instrumentos legales -como la prohibición de la difusión de medios anticonceptivos o penalización del aborto-, subvenciones y facilidades fiscales a las familias numerosas. Todo ello con la difusión de la ideología natalista como instrumento para alcanzar una población total de cuarenta millones de habitantes en España. Pero el comportamiento real de la sociedad siguió caminos diametralmente opuestos al objetivo de la política oficial. Frente al propósito de aumentar la natalidad, ésta va a iniciar un descenso continuado desde los inicios del desarrollo económico en los años sesenta.

La natalidad en España va a cambiar su tendencia histórica en un contexto fuertemente adverso a su reducción. En los años sesenta aumenta la nupcialidad y se reduce la edad de matrimonio; se casan, pues, más mujeres y más jóvenes. Esta acumulación de matrimonios, que tuvieron entonces sus primeros hijos, mantuvo hasta 1964 muy elevada la tasa bruta de natalidad. Pero porque se formaron entonces más matrimonios.

Los años sesenta significan, pues, un rápido proceso de aproximación de la natalidad española a la imperante en otros países europeos desarrollados. Se inicia entonces la tendencia continuada a la reducción de la fecundidad de las mujeres casadas de todas las edades. Pero sobre todo de las más jóvenes. $Y$ el descenso es más acusado y rápido en las familias numerosas (con cuatro o más hijos), que, pese a su fomento legal, pierden peso relativo en el conjunto de los hogares.

Estas tendencias demográficas se corresponden además con la natalidad deseada. El número de hijos considerado ideal, analizado en numerosos estudios de opinión, oscila entre dos y tres, desciende desde los años sesenta y es más bajo entre los sectores más jóvenes de la población.

La evolución de la natalidad en España a partir de los años sesenta revela, pues, que las mujeres españolas emplean cada vez más métodos eficaces de limitación de los nacimientos. Y ello a pesar de los obstáculos legales existentes y a la ideología oficial natalista. Es decir, España completa la última fase de la «transición demográfica» (descenso de la natalidad y mortalidad) modernizando sus comportamientos demográficos. Progresivamente, las parejas deciden el número de hijos que tienen y cuándo los tienen, y existe una creciente adecuación entre el deseo y la realidad.

Los cambios fueron igualmente profundos y rápidos en las actitudes y comportamientos en relación a la familia. Se modifica la estructura de autoridad y la toma de decisiones dentro de la familia. La distribución de tareas domésticas atenúa su carácter sexista. Las relaciones intergeneracionales pierden contenido autoritario. El movimiento feminista inicipiente cuestiona en 
profundidad la situación de la mujer y de la familia. Se incrementa paulatinamente la aceptación social del divorcio y los conflictos matrimoniales comienzan a hacerse frecuentes. La aparición de estos conflictos -en sí mismo exponente de formas modernas de familia - vino impulsada por la quiebra de los mecanismos formales de mantenimiento de las apariencias de estabilidad matrimonial: el anonimato urbano, la independencia económica lograda por la mujer con su acceso a la población activa, la secularización religiosa, etc. Los mismos efectos del desarrollo económico permitían que vieran luz pública conflictos que antes hubieran quedado ocultos en una coexistencia matrimonial vacía.

En definitiva, los cambios significan la pérdida de hegemonía de la familia tradicional y su sustitución por la familia moderna y nuclear. $O$, si se quiere, el paso de la familia como institución a la familia fundada en la interacción personal. Un cambio efectuado en un contexto ideológico y con ortodoxia oficial hostil a la dirección modernizadora que adoptó. El cambio político, por consiguiente, sobrevino cuando los comportamientos y las actitudes mayoritarias de la sociedad habían transformado la familia española. La modificación de la legislación familiar no hizo sino ajustar la ley a los hechos, ahora sí -y no durante la Segunda República- congruentes.

No podía, por tanto, suscitar tensiones graves un cambio legal en la familia que previamente había sido asumido por la población. Los profundos cambios sociales durante los últimos quince años del franquismo requerían el cambio del ordenamiento jurídico familiar. La transición suprimió desajustes previos. En este aspesto es por completo aplicable el juicio formulado por Felipe González: «Si algo ha demostrado esta sociedad, es que ya, antes de la muerte de Franco, estaba viviendo con actitudes que no correspondían con la costra superestructural que representaba al franquismo. Sin esa realidad no hubiera sido posible el cambio democrático» (10). Esto, por lo menos, fue lo ocurrido con costumbres y hábitos familiares.

(10) Declaraciones del presidente del Gobierno, Felipe González, al director de Diario 16, en dicho diario el 19-XII-1986, pág. 9. V. PÉREz DíAz ha puntualizado al respecto que «a veces se muestran los quince o veinte últimos años del franquismo como el escenario de una 'contradicción' entre una estructura socioeconómica que cambia y una estructura política que se resiste a cambiar, y cuyo resultado final es la transición política, que restablece la congruencia entre sociedad y economía de un lado y sistema político de otro. Esta teoría es errónea en la medida en que minimiza el efecto de los factores culturales y simplifica excesivamente el juego de relaciones recíprocas entre política y factores socioeconómicos. Y uno de sus varios puntos débiles consiste justamente en no dar cuenta de los cambios políticos del régimen franquista en los últimos quince o veinte años» (El retorno de la sociedad civil, Instituto de Estudios Económicos, Madrid, 1987, pág. 444). 


\section{LOS CAMBIOS EN LA IGLESIA ESPAÑOLA}

Las innovaciones introducidas por el sistema político en la regulación de la familia no han originado tensiones o conflictos graves. Como consecuencia también del papel desempeñado por la Iglesia. Su actitud puede catalogarse como tolerante o comprensiva ante modificaciones legales que, por una parte, suprimían su control sobre la regulación de la familia, y por otra, rompían con la orientación defendida por la Iglesia. Este calificativo de comprensión y tolerancia es aplicable a nivel institucional -la Conferencia Episcopal Española-, aunque no hayan faltado reacciones más duras por parte de obispos concretos. Pero en ningún caso ha habido una pretensión de movilización social en contra de las nuevas directrices jurídicas sobre la familia, bien sea por convicción propia o por asumir la secularización de la sociedad española.

Históricamente, la actitud del Estado ante el hecho religioso ha sido siempre beligerante en la sociedad española: o a favor exclusivo y privilegiando a la Iglesia católica, o contra ella. $O$ el confesionalismo o la anticonfesionalidad, pero siempre motivo de enfrentamiento y polémicas. El franquismo y la Segunda República constituyen ejemplos notorios de esta actitud, siempre radical y dirigida contra un sector de la sociedad española.

Sin embargo, la Iglesia había cambiado profundamente en las dos últimas décadas del franquismo. Unos cambios que facilitaron la transición política y la modificación del régimen legal de la familia. Sus raíces se encuentran en acontecimientos exteriores, pero cuya repercusión facilitó la acentuación por parte de la Iglesia de la nueva situación.

El primer desencadenante externo del cambio fue el Concilio Vaticano II. Su impacto ha sido decisivo. Sin él resulta difícil comprender no sólo la posición de la Iglesia española, sino muchas peculiaridades de la transición política a la democracia. En el Concilio Vaticano II, en efecto, «reside la explicación inmediata del carácter súbito del aggionnamento ideológico y del comportamiento del catolicismo español. Por una pare, las normas conciliares fueron recibidas como medidas disciplinarias, aunque insoslayables, por la fracción más conservadora de la Iglesia de España. Por otra parte, aportaron a su fracción liberal la legitimidad que aún en parte le faltaba, y que le permitió inclinar la balanza de la institución religiosa» (11). A partir de entonces, la Iglesia inicia una etapa de distanciamiento y moderada oposición frente al poder.

(11) G. HeRmet: Los catolicos en la España franquista, vo1. 2.", CIS, Madrid, 1986, págs. 491-492. 
Esta evolución situó a la Iglesia en una posición institucional más proclive a admitir la autonomía de la sociedad civil y a no radicalizar sus demandas ante la reforma de la legislación familiar. Gracias a las directrices del Concilio, la Iglesia comienza a aceptar que la legislación civil no debe imponer coactivamente las creencias religiosas, sino aceptar el pluralismo. El propio Hermet subraya la participación del clero, como pedagogos de la reforma laica, en una sociedad impregnada de valores religiosos. Sin su actuación, el proceso de secularización hubiera resultado truncado y desprovisto de legitimidad. Aquellos sacerdotes que adoptaron una postura contraria dejaron de representar a la Iglesia en el último decenio del franquismo (12).

Pero, además, existió otro estímulo externo actuando en la misma dirección, y específicamente respecto a la legislación familiar. Se trata de la experiencia italiana de 1974, muy poco antes de la transición española: el fracaso de la movilización puesta en práctica por la Iglesia en el referéndum para abrogar el divorcio. Su resultado sirvió como ejemplo a evitar. Reveló, en efecto, cómo sociedades consideradas católicas $-\mathrm{y}$ con partido político confesional de gran implantación social - no siguen las directrices de la Iglesia. Optan, por el contrario, por apoyar innovaciones laicas en la regulación de la familia. Comprometer a la Iglesia española en una aventura semejante resultaba de dudosa eficacia y alto riesgo, cuando tan reciente estaba el ejemplo italiano. El costo de la operación hubiera podido comprometer la estabilidad del naciente sistema democrático $\mathrm{y}$, desde luego, la posición de la propia Iglesia (13).

El antecedente italiano, por tanto, favoreció la adopción por la Iglesia de posturas prudentes en este terreno. También el rechazo de movilizaciones sociales con búsqueda de logros por la vía de la negociación con el poder político durante la transición política. Y posiblemente con más énfasis en los intereses educativos que en la regulación de la familia. La existencia de una opinión pública mayoritariamente favorable al divorcio - constatada en numerosos estudios - reforzaba la tendencia a la tolerancia y la huida de

(12) G. HeRmet: op. cit., pág. 493.

(13) Esto explica la ausencia de referencias al referéndum por sectores eclesiásticos. Una excepción, sin embargo, fue la de J. M.. Martín Patino, influyente vicario general de la archidiócesis de Madrid con el cardenal Tarancón, quien declaraba: «El hecho de que se conceda libertad para casarse o no por la Iglesia a los ciudadanos españoles bautizados no prejuzga, en absoluto, la determinación que en su día pueda tomar el poder legislativo español para admitir o no el divorcio civil. Eso es harina de otro costal. Y yo creo que antes de admitir el divorcio habría que preguntar sobre esto a todos los españoles», en declaraciones al semanario Gaceta Itustrada, núm. 1.017, 4 abril 1976, pág. 49. 
posiciones drásticas ante el cambio de signo de la legislación familiar. Una actitud impulsada, en último término, por la propia estrategia de la reforma. Su naturaleza paulatina y sucesiva impidió ciertamente la globalización y radicalización de las discrepancias.

Pero debe señalarse un tercer desencadenante externo, que igualmente desbrozó la evolución legal de la familia sin conflictos graves con la Iglesia. El impulso vino en este caso de Portugal. Tras la Revolución de 1974, la Santa Sede aceptó suscribir un protocolo adicional del Concordato con ese Estado en 1975. Fueron así suprimidas las normas que impedían a los matrimonios canónicos acceder a la ley civil del divorcio. Esta actitud de la Iglesia se produce ciertamente un año después del fracasado referéndum antidivorcista italiano; posiblemente también para evitar la denuncia unilateral del Concordato por parte del Estado portugués. Y en la época de Pablo VI, cuando en España se va a desencadenar en la de Juan Pablo II. La situación, obviamente, no es la misma, pero el camino vino también facilitado por la solución dada al problema pendiente de resolver en España.

Junto a estos factores externos, otro elemento interno situó a la Iglesia española en posición de debilidad para la defensa de su concepción de la legislación familiar. No fue otro que la profunda crisis de los Tribunales eclesiásticos. El Concordato entre el Estado y la Santa Sede de 1953 otorgó a la Iglesia en España la competencia para juzgar las causas de nulidad y separación matrimonial de los matrimonios contraídos en forma religiosa (más del 95 por 100 durante el franquismo). Con las transformaciones de la familia desde los años sesenta aumentan considerablemente las demandas ante dichos Tribunales. Al mismo tiempo aparecen insistentes denuncias públicas sobre tardanzas indefinidas en la tramitación de las demandas, acusaciones de parcialidad, elevado coste económico, sobornos o corrupciones y errores. Además, extensos sectores de la sociedad española cuestionan la legitimidad de la competencia judical otorgada a la Iglesia, sobre todo en el caso de parejas que declaran haber abandonado toda práctica religiosa. Junto a todo esto, sectores privilegiados de clase alta obtienen sentencias de nulidad matrimonial (que, en realidad, son divorcios encubiertos), con tramitación breve y altos costes económicos, en Tribunales eclesiásticos de otros países (fundamentalmente Estados Unidos), pero cuyas decisiones son directamente ejecutables en España (14). Esta situación, en definitiva, deterioró profundamente la capacidad negociadora de la Iglesia y convenció a extensos sectores de la población española — incluidos, probablemente, los de la propia

(14) Junto a numerosos testimonios publicados en la prensa desde 1965, véase A. Aradillas: Proceso a los Tribunales eclesiásticos, Ed. Sedmay, Madrid, 1974. 
jerarquía eclesiástica - de la necesidad de abandonar las prerrogativas eclesiásticas en la legislación familiar y aproximarse a los esquemas vigentes en otros países europeos. A los creyentes, por los efectos negativos para la Iglesia, y al resto de la sociedad, por considerarlo propio de la soberanía del poder civil.

Esto no significa, como es obvio, que el proceso haya carecido de tensiones o conflictos. Se han producido, con alcance limitado, orientados a la defensa de sus convicciones, pero sin cuestionar la legitimidad de decisiones opuestas. Una actitud radicalmente opuesta a la desencadenada, ante las mismas cuestiones, durante la Segunda República.

La prensa de la época, en fechas previas a la aprobación de la Constitución, conservan numerosas declaraciones de obispos con posturas matizadas sobre el divorcio. El propio presidente de la Conferencia Episcopal, cardenal Tarancón, ante la posibilidad de abordar la regulación del divorcio, sostenía la existencia de problemas prioritarios para la consolidación de la democracia, como el regional o el económico, añadiendo: «Yo creo que lo del divorcio y el aborto no saldrá tan pronto a la palestra como tú crees. Pienso que tendrán suficiente sentido común como para, teniendo como tienen problemas tan urgentes y prioritarios en las manos, distraerse en esas cuestiones de ideología. Además, en última instancia, la Iglesia sólo legisla sobre el matrimonio cristiano y sobre los católicos. La cuestión del matrimonio civil es competencia del Estado, y en eso, allá ellos. Pero, en fin, de todas maneras, no creo que haya dificuttades insuperables. El simple hecho de que el Gobierno sea de gente muy joven determina que comprendan mejor la situación y actitud de la Iglesia» (15).

Esta misma actitud se manifiesta en el documento sobre «La estabilidad del matrimonio", aprobado por la Comisión Episcopal para la Doctrina de la Fe en mayo de 1977. En él, por primera vez colectivamente, los obispos adoptan una postura de tolerancia ante la posibilidad de introducir una ley civil divorcista. Reafirmando que el divorcio es un mal para la sociedad, añaden que: «No significa que el legislador esté obligado a elevar a la categoría de norma legal todo lo que es una exigencia ética o que debe reprimir con medidas legales todos los males en la sociedad» (16). Llegan incluso a solicitar el cambio de la legislación para la regulación del matrimonio civil en virtud del principio de libertad religiosa.

Este documento tiene sin duda importancia. Primero por su propio contenido, pues los obispos dejan al criterio del legislador la orientación a dar

(15) Declaraciones del cardenal Tarancón en Gacela Ilustrada, núm. 1.084, 17 de julio de 1977, pág. 74.

(16) Recogido en el semanario Vida Nueva, 14 mayo 1977, págs. 23-30. 
al matrimonio y divorcio. Pero también por el momento en que el texto se divulga: dos meses antes de las primeras elecciones generales. Con ello se distanciaban de intentos de partidos políticos en presentarse como portavoces de las posiciones eclesiásticas ante el divorcio y familia.

En septiembre de 1978, la Comisión Permanente de la Comisión Episcopal Española aprobó una nota sobre el referéndum constitucional, a celebrar el 6 de diciembre. Reconocían los valores de la Constitución, pero mostraban reservas al tratamiento de la enseñanza y la familia y su esperanza en el correcto desarrollo legislativo de la Constitución. Esta nota fue posteriormente aprobada por la Asamblea del Episcopado.

Sin embargo, el conflicto fue desencadenado por el cardenal primado de Toledo - que había perdido la votación en la Asamblea-. Publicó, en efecto, una "Carta pastoral ante el referéndum constitucional», juzgando, en términos muy severos, la Constitución, en la que, a la luz de la concepción cristiana de la sociedad, aparecen elementos muy negativos. Entre otros aspectos señalaba la falta de claridad en el tema del aborto, ausencia de garantías de libertad de enseñanza y que la Constitución no tutela los valores morales de la familia: «que, por otra parte, están siendo ya agredidos por la propaganda del divorcio, de los anticonceptivos y de la arbitrariedad sexual», y añade que «abre la puerta para que el matrimonio, indisoluble por derecho divino natural, se vea atacado por la peste de una ley de divorcio, fábrica ingente de matrimonios rotos y de huérfanos con padre y madre" (17). Implícitamente se propugnaba el voto negativo a la Constitución, y ocho obispos de los setenta de la Conferencia se hicieron públicamente solidarios con su posición.

Junto a estas escaramuzas por el contenido de la Constitución, se desarrollaron unas largas negociaciones entre el Estado español y el Vaticano para la supresión del Concordato de 1953. Los acuerdos fueron suscritos, casi simultáneamente a la aprobación de la Constitución, el 3 de enero de 1979, y también las principales dificultades aparecieron en la enseñanza y la familia. En los acuerdos de carácter jurídico se produce una modificación sustancial de la actitud anterior de la Iglesia al aceptar la competencia de los Tribunales civiles en los matrimonios canónicos (18).

(17) El texto del primado, monseñor González Martín, en El País, 29-XI-1978. Véase también para estos aspectos J. M. LABOA: "Iglesia y religión en la España democrática», en AA. VV.: Diez años en la vida de los españoles, Ed. Plaza y Janés, Barcelona, 1986, págs. 59-101.

(18) Los acuerdos fueron ratificados por las Cortes democráticas; para el análisis de su contenido, véase E. Fosar Benlloch: Estudios de derecho de familia, vol. 1. ${ }^{\circ}$, Ed. Bosch, Barcelona, 1981, caps. 9-16. 
El contenido de dichos acuerdos resolvía por adelantado futuras controversias mediante el reconocimiento de la competencia civil. La Constitución, en su artículo 32.2, establece que la ley regulará «las causas de separación y disolución y sus efectos». El divorcio, eufemísticamente designado con la palabra «disolución», pudiera haber originado interpretaciones restrictivas en el sentido de afectar únicamente al matrimonio contraído en forma civil y no al canónico. Sin embargo, con los acuerdos se despejó sin tensiones el futuro desarrollo legislativo. La Iglesia admite que los casados canónicamente puedan obtener la declaración de nulidad ante los Tribunales eclesiástico o ante los Tribunales civiles aplicando el derecho estatal. En caso de optar por los Tribunales eclesiásticos, sus decisiones sólo tendrán efectos civiles una vez declaradas ajustadas al derecho del Estado por los Tribunales civiles. Respecto a la separación matrimonial, el silencio del acuerdo jurídico priva de posible eficacia en el orden civil a las decisiones de los Tribunales eclesiásticos.

La propia Santa Sede era consciente de la inminente introducción del divorcio en la legislación española. Y, lo que resulta más importante, despeja el camino para su futura regulación aceptando que incluya también al matrimonio religioso (y no sólo al civil). El texto del Acuerdo sobre asuntos jurídicos contiene, como manifestación unilateral, la declaración de que «la Santa Sede afirma el valor permanente de su doctrina sobre el matrimonio y recuerda a quienes celebren matrimonio canónico la obligación grave que asumen de atenerse a las normas canónicas que lo regulen, y en particular respetar sus propiedades esenciales». Con esta declaración, la Iglesia, tácitamente, consiente, sin necesidad de nuevo acuerdo, que el Estado extienda la legislación civil del divorcio a los matrimonios contraídos en forma canónica; como así sucedió, en efecto, con la Ley de 1981. Pero, sin duda, con su postura quedaba neutralizada la posible futura controversia sobre el ámbito de aplicación del divorcio.

En 1979, por tanto, la introducción del divorcio y su extensión al matrimonio canónico eran cuestiones prácticamente resueltas con la aceptación de la Iglesia y la mayoría del Episcopado español. Restaba precisar el alcance de la tolerancia. El proyecto de ley de divorcio de UCD fue consultado por el entonces ministro de Justicia, señor Cavero, con la Iglesia, y fue aprobado por el Consejo de Ministros el 25 de enero de 1980. Contemplaba el divorcio por mutuo acuerdo pasados cuatro años ininterrumpidos de cese efectivo de la convivencia conyugal. Y en esta cuestión se centrará la crítica por el Episcopado español.

Antes de aprobarse el proyecto, la Conferencia Episcopal Española se apresuró a rechazar el divorcio consensual. Por 59 votos a favor, 2 en contra 
y 4 en blanco, aprobó el 23 de noviembre de 1979 un duro documento, señalando: «Consideramos que es absolutamente inaceptable el llamado divorcio consensual. Una ley que introdujese el divorcio, de tal manera que la pervivencia del vínculo quedase a disposición de los cónyuges, sería rechazable moralmente y no podría ser aceptada por ningún católico, ni gobernante ni gobernado." El texto contiene un abierto rechazo del divorcio. Sin embargo, lo más notable es que, según el obispo de Cuenca, monseñor Guerra Campos, tal actitud fue resultado de una intervención directa de la Santa Sede para dar al texto un rigor crítico y dureza, previamente inexistente: «Una intervención directa de la Santa Sede - dice-, a última hora, impidió que los obispos aprobasen una declaración expresa de licitud a la decisión política que establece una ley civil del divorcio» (19).

En la última fase de la introducción del divorcio, la superposición de conflictos que origina hace pasar a un segundo plano la reacción del Episcopado. La ley del divorcio activó, en efecto, la crisis del partido gobernante -UCD- con las divisiones ideológicas de sus diferentes sectores (20). Precisamente cuando se iniciaba el II Congreso de dicho partido, en febrero de 1981, la Comisión Permanente del Episcopado se pronuncia de nuevo sobre el tema, en términos semejantes al de 1979, contrarios al divorcio por consentimiento mutuo. Aprobada por el Parlamento la nueva Ley, en junio de 1981, la Comisión Permanente del Episcopado publica una nueva declaración. En ella lamenta su aprobación por el grave daño a la estabilidad del matrimonio y por dejar al arbitrio de los cónyuges la disolución. Sin embargo, su contenido se centra en los aspectos pastorales que el divorcio plantea a la Iglesia.

En definitiva, el influjo de factores externos y los cambios internos de la Iglesia española posibilitaron un cambio en la legislación familiar con mínimos costes de conflictos con el Estado. Su postura se orientó a intentar evitar el divorcio por consentimiento mutuo sin planteamientos de principio. Las apelaciones que efectúa son a los legisladores, para que tengan presente

(19) El documento de la Conferencia Episcopal, en el diario Ideal (Granada), 29-XI-1979, y las afirmaciones de monseñor Guerra, en El País, 6-XII-1979, pág. 14.

(20) Véase un sumario análisis de los efcetos de la Ley de Divorcio en la crisis de UCD, en C. Huneeus: La UCD y la transición a la democracia en España, CIS, Madrid, 1985, págs. 339-348, y en LaboA: op. cit. Además de los efectos en la cohesión interna del partido - único aspecto que suele mencionarse-, parece que también originó costes electorales su postura modernizadora de la legislación familiar. El haber hecho la Ley del Divorcio e ir contra a familia es la cuarta razón que más ha influido en la transferencia de votos de UCD a AP en 1982; véase R. López Pintor y M. JusTEL: «Iniciando el análisis de las elecciones generales de octubre de 1982», en Revista Española de Investigaciones Sociológicas, núm. 20, 1982, pág. 165. 
sus concepciones sobre el matrimonio, sin intentar movilizar a la sociedad como instrumento de presión. Adoptó una posición contemporizadora. $Y$ ésta no parece ser la norma. Años después, en 1986, se plantea en Argentina. Entonces la Comisión Permanente del Episcopado excomulgó a los diputados que votaron a favor del divorcio, a menos que se retracten públicamente de su voto ( $A B C, 26$ octubre 1986, pág. 67).

\section{LAS ESTRATEGIAS POLITICAS ANTE LA LEGISLACION FAMILIAR}

La ausencia de conflictos institucionales entre la Iglesia y el Estado por la reforma de la legislación familiar se ha visto favorecida igualmente por las decisiones políticas. Víctor Pérez Díaz ha señalado las raíces de la armonía entre la Iglesia y los dirigentes políticos democráticos. En primer lugar, los líderes tradicionales de la oposición habían abandonado sus posiciones antirreligiosas y anticlericales de la guerra civil. En segundo lugar, la nueva clase política había sido formada en parte por la Iglesia o proporcionado recursos organizativos, fraguando pautas de diálogo entre sus diversos sectores, durante la oposición clandestina. $Y$ en tercer lugar, el hecho de que no se llegara a crear un partido demócrata cristiano posibilitó igualmente las buenas relaciones con la Iglesia de nuevos dirigentes políticos de la democracia. Con ello, éstos dejaban de temer la competición de la Iglesia en su propio terreno (21).

Estas actitudes tuvieron efectos notables en el proceso de transición y favorecieron diversas estrategias de consenso. En la propia Constitución se encuentran manifestaciones de esa estrategia de compensación, ambigüedad y eliminación. Esto es, inserción de artículos lógicamente contradictorios que permitan a grupos dispares encontrar en el texto el reflejo de sus preferencias; redacción deliberadamente vaga de otros susceptibles de interpretaciones complementarias cuando no contradictorias, y por último, remisión del problema expresa o implícitamente a un futuro desarrollo legislativo. Futuro que, según la situación política que se tratase, se configuraría de una u otra manera, pero que ya se producía fuera de la órbita constitucional. El desacuerdo con las hipotéticas disposiciones no se traduciría de inmediato, al menos en principio, en desacuerdo con la propia Constitución (22).

(21) V. Pérez Díaz: op. cit., págs. 455-456.

(22) Me he ocupado de cstos aspectos con más detenimiento, pero referido al aborto, en El aborto. Un estudio sociológico sobre el caso español, CIS, Madrid, 1979. Un análisis más detallado se encuentra en R. DEL Aguila y R. Montoro: El discurso político de la transición española, op. cit., cap. $4 .^{\circ}$ 
Con esta estrategia, en definitiva, se evitaba que el texto constitucional apareciera innecesariamente "cargado" de contenidos políticamente secundarios, pero altamente conflictivos en el plano simbólico y emocional (comosucedió en la Constitución de la Segunda República con el tratamiento de la cuestión religiosa), que concitaban de manera gratuita al enfrentamiento con la Constitución de grupos sociales significativos.

Sin duda ninguna, la cuestión del divorcio fue una de las materias sacrificables mediante el consenso, y a la vez, para no obstaculizar el consenso. Hay en ello una curiosa ambivalencia. Sacarlo de la Constitución para que no obviara el consenso parece acreditar la sensibilidad política y ciudadana. sobre el tema. $\mathrm{Si}$, en principio, no se le hubiera concedido notable importancia no parecería necesario ocuparse de evitar que dañara el acuerdo entre los grupos políticos. Por otra parte, si se hubiera considerado materia fundamental no hubiera podido quedar al margen de la regulación constitucional. ¿Qué explica la ambivalencia? En mi opinión, que el tema se encontraba más vivo en la sociedad civil, aunque fuera dentro de grupos minoritarios, que en la elite política. Los partidos no podían ignorarlo por su presencia en aquélla. Tampoco convertirlo en cuestión esencial, porque no era tal desde su óptica y especialmente desde lo que pudiera denominarse su «óptica electoral». El análisis de María Angeles Durán (23) de la campaña electoral de. 1977 muestra la limitada relevancia otorgada al divorcio y, en general, a la familia por los distintos partidos.

Condenado, pues, el divorcio al consenso precisamente para no romper el consenso, el tratamiento que recibe utiliza la vía que he denominado de la ambigüedad. En la Constitución no aparece el divorcio; no lo constitucionaliza. Pero contempla eufemísticamente su implantación futura. Se remite: al ordenamiento jurídico ordinario, disponiendo en el párrafo $2 .^{\circ}$ del artículo 32, dedicado al matrimonio, que la ley regulará - entre otras materias-. las causas de separación y disolución y sus efectos. Esta redacción no prejuzga la regulación del divorcio en ninguna dirección: ni lo impone ni lo impide. Lo deja abierto al legislador ordinario para resolverlo de acuerdo como intérprete más adecuado a la realidad social.

Pero lo importante no es tanto la ambigüedad, como que ésta es deliberada. Se quiere tratar y, al tiempo, no tratar el divorcio; que conste, pero que no. conste en el texto constitucional. En definitiva, una maniobra de exhibición y ocultamiento. La prueba de ello se encuentra en los votos particulares, en-

(23) M. A. DURÁN: «Ideología política y modelos familiares», en $R E O P$, núm. 50, 1977; para las elecciones de 1982, véase Informe sociológico sobre el cambio social en: España, 1975-1983, vol. 2.․, Madrid, 1983, págs. 463 y sigs. 
miendas al proyecto constitucional (que no sufrirá modificación) y los debates parlamentarios. El divorcio se aborda frontalmente, se demanda el divorcio por mutuo consentimiento y por causa legal. Sin embargo, se elude consignarlo explícitamente, y eso en aras del consenso político, de la atenuación de conflictos con la Iglesia y, posiblemente, por no calibrar los efectos electorales que pueda tener una posición abiertamente divorcista. La ausencia de una postura definitiva sobre el divorcio en la Constitución fue explotada políticamente. El presidente del Gobierno, Adolfo Suárez, al pedir el voto afirmativo en el referéndum sobre la Constitución, afirmó: «No es cierto que la Constitución consagre el aborto, proclame el divorcio, prescinda de la familia, deje de garantizar la libertad de enseñanza ni atente contra la ciudad de España» (24).

La estrategia de la ambiguiedad favoreció sin duda la ausencia de conflictos en el cambio de la legislación familiar. Sobre todo porque vino acompañada de otra estrategia que podemos denominar de escalonamiento del cambio legal. El cambio simultáneo de todo el ordenamiento jurídico familiar habría provocado el aumento de expectativas y movilizaciones sociales $\mathrm{y}$, con ellas, la acumulación de demandas -inevitablemente contradictorias - respecto a la orientación y contenido de los cambios propuestos. En suma, habría alimentado las fuentes de conflicto y hecho peligrar la propia reforma.

Frente a ello, la vía adoptada resultó a la postre la más fructífera y con menos desgaste para el poder político. Las reformas legales se han planteado sucesivamente como reformas parciales del derecho de familia. Pero, en conjunto, han originado, en breve plazo, la reforma total de la legislación familiar -en ruptura con la orientación ideológica que la condicionaba durante el franquismo-, hoy ya semejante a la vigente en los países europeos democráticos. En las secuencias del cambio gradual pueden señalarse algunas referencias.

En lo que se refiere al control de la maternidad, las modificaciones legales se suceden desde antes de la aprobación de la Constitución. Así, en octubre de 1978 se despenalizó la venta, propaganda y difusión de los anticonceptivos. En 1983 se despenaliza igualmente la esterilización voluntaria y se aprueba, el mismo año, la despenalización parcial del aborto. Estas medidas legales vinieron acompañadas de la paulatina implantación de centros públicos de orientación y planificación familiar.

Respecto a la regulación de la sexualidad, los cambios en la legislación

(24) Intervención del presidente Adolfo Suárez en Televisión Española el 4 de diciembre de 1978, reproducida en el diario $Y a, 5-\mathrm{XII}-1978$, pág. 12. 
se inician también desde antes de la Constitución. En mayo de 1978 fueron despenalizados los delitos de adulterio y amancebamiento, suprimiendo disposiciones previas que sancionaban a la mujer por un solo acto de infidelidad conyugal, mientras para condenar al marido se exigía mantener notorias relaciones adúlteras o introducir a la amante en el domicilio conyugal. En octubre del mismo año se modifica la regulación del delito de estupro y rapto, en el sentido de poder ser sujeto pasivo del mismo, no la mujer, sino la persona, equiparando, por tanto, a los dos sexos. Además, se suprimen los requisitos de carácter moral que se exigían a la mujer para poder ser considerada víctima del delito de estupro: doncellez y acreditada honestidad. En 1983 y 1984 se modifica la regulación de los delitos contra la honestidad y reducen la eficacia jurídica del perdón en los delitos de violación, abusos deshonestos, estupro y rapto. En la violación, el perdón no extingue la acción penal, y en los otros supuestos, sólo si se pronuncian antes de recaer sentencia y de manera válida para el derecho.

La modificaciones legales son importantes también en el ámbito de la situación jurídica de los hijos. En 1981, por ley se igualan en derechos a los hijos matrimoniales y no matrimoniales. Además, se admite la investigación de la paternidad. En mayo de 1982 se produce la reforma del Código Civil en materia de tutela, que promueve mayor grado de intervención judicial en beneficio del menor. Y en julio de 1982 se establece la nacionalidad española de origen para los hijos de madre española, aunque el padre sea extranjero.

Los cambios han sido también importantes con la equiparación juridica de los cónyuges. La principal ley fue la de mayo de 1981, sobre patria potestad y régimen económico del matrimonio. Por primera vez en la legislación ordinaria se comparte entre el padre y la madre el ejercicio de la patria potestad respecto a los hijos, suprimiendo la anterior subordinación de la mujer al marido. La misma orientación contiene el cambio del régimen económico patrimonial. Sitúa en plano de igualdad al marido y a la mujer en la administración y disposición de bienes gananciales y declara nulo cualquier pacto que limite la igualdad de derechos entre los cónyuges. La Ley de 1981 regula, en un plano de igualdad entre ambos, los derechos y deberes entre los cónyuges. Respecto al domicilio conyugal, la ley determina que se fijará de común acuerdo, y en caso de discrepancia —en lugar de la prerrogativa en favor, de hecho, del marido, existente con anterioridad-, resolverá el juez atendiendo el interés de la familia.

Por último, se introduce de nuevo, tras el paréntesis de la Segunda República, la Ley de Divorcio, del 7 de julio de 1981. La importancia de la innovacion radica en que permite disolver el matrimonio tanto si se ha celebrado en forma religiosa como en forma civil (no se hace eco, pues, de ciertas 
pretensiones de hacerla aplicable sólo para el civil, que hubiera anulado prácticamente la efectividad de la ley). La ley considera tanto el divorcio por mutuo acuerdo — con procedimiento simplificado y más rápido- y sin él. Restringe además considerablemente la intervención del juez, que, en algunos casos, queda reducido a dar fe y, por tanto, trascendencia legal a los planteamientos de ruptura de los cónyuges. Pero sin ninguna capacidad decisoria de denegación del divorcio si hay acuerdo entre las partes o se solicita por una con el consentimiento de la otra. No sólo para el divorcio, sino también para la separación y nulidad matrimonial, los Tribunales civiles son los úni* cos con competencia y cuyas decisiones producen efectos civiles. Su regulación viene contenida también en esta ley, pero la Iglesia había renunciado ya a la jurisdicción en materia de separaciones y nulidades por el acuerdo entre el Estado español y la Santa Sede firmado el 3 de enero de 1979.

Este conjunto de modificaciones legales - a las que cabría añadir otras referidas a derechos de la mujer y múltiples disposiciones de rango inferior a ley- ha modificado por completo el marco legal de la familia española. $Y$ sin suscitar conflictos o tensiones en la sociedad: «A nivel de la legislación se ha producido una verdadera puesta al día, en la que los viejos valores que inspiraban y configuraban el modelo de familia tradicional en la legislación anterior han sido sustituidos y han dado paso a una concepción de la familia moderna imperante en otros países europeos» (25).

Un siglo después de la polémica sobre el matrimonio civil, la familia y su ordenación jurídica han completado un ciclo conflictivo. Se ha cerrado, en efecto, un desajuste casi permanente, que ha condicionado la vida política.

En conjunto, pueden señalarse cuatro fases: Durante la Segunda República, la legislación familiar se encontraba más avanzada a las costumbres predominantes en la sociedad española, entre otras razones por el retraso económico, ruralismo, subordinación de la mujer, etc. El derecho se empleó -al menos en el ámbito de la familia y costumbres- como instrumento de cambio social. Sus efectos no pudieron hacerse notar con eficacia. La experiencia innovadora fue excesivamente limitada en lo temporal, para que rompiera con hábitos seculares.

La segunda fase se sitúa en el franquismo posterior a la guerra civil y hasta los años sesenta. Se anulan todas las innovaciones republicanas, volviendo a implantarse la legislación tradicional sobre la familia. En mi opinión,

(25) Informe sociológico..., cit., pág. 508. 
en gran parte el tradicionalismo legal se correspondió con el familiar y de costumbres durante este período (26). Naturalmente, esta correspondencia no era espontánea, sino también forzada: la censura, la imposición de ortodoxias oficiales religiosas y civiles, el temor a represalias por desviaciones, la pobreza generalizada y tantos otros factores influyeron decisivamente. Pero el resultado impuesto fue una correspondencia global entre la legislación familiar y la situación de la familia.

La tercera fase está vinculada al despegue económico de los años sesenta. En ella se invierte la situación de la República. De nuevo se producen desajustes entre el derecho y la situación real de la familia. Pero en esta ocasión son las costumbres las que avanzan, y el marco legal el que queda rezagado. Ahora es la sociedad la que reclama el cambio de la legislación.

La última fase es la transición y supone el ajuste entre el derecho y la realidad social. Por ello ha podido realizarse el cambio de la legislación familiar sin conflictos y tensiones. Porque el conflicto se situaba en el pasado y el cambio vino a anularlo. Otra cuestión es en qué medida los legisladores actuales tendrán capacidad de respuesta a situaciones familiares hoy emergentes. Pero esto ya no es objeto del presente trabajo.

(26) Sustancialmente comparto la opinión de dos historiadores, RAYMond CARR y JUAN PABLo FuSI, cuando afirman: «El régimen de Franco representó una restauración de valores tradicionales sobre la educación, la familia, la religión y el orden social, que estaban bastante más arraigados en la sociedad española de lo que creyeron los reformistas liberales de los años treinta» (España: de la dictadura a la democracia, Ed. Planeta, Barcelona, 1979, pág. 179). 